\title{
Social isolation and Life satisfaction mediating the association of ADL and mild cognitive impairment in rural older adults:A multi-group SEM with latent response variable mediation analysis
}

gaizhen jia ( $\square$ jiagzh221@163.com)

Binzhou Medical University - Yantai Campus

\section{Research Article}

Keywords: mild cognitive impairment, social isolation, life satisfaction, ADL, indirect effect

Posted Date: February 21st, 2022

DOI: https://doi.org/10.21203/rs.3.rs-1291389/v1

License: @ (i) This work is licensed under a Creative Commons Attribution 4.0 International License. Read Full License 


\section{Abstract}

Background: There are many studies on the relationship between daily activity ability (ADL) and mild cognitive impairment (MCl), and only the discussion of the relationship between $\mathrm{ADL}$ and $\mathrm{MCl}$. However, the mechanism of the potential difference is very important to reduce the impact of cognitive dysfunction in later life. The purpose of this study was to investigate whether social isolation and life satisfaction mediated the relationship between ADL and MCl in the older adults.

Methods: A village-based cross-sectional study was conducted among 2,933 older adults people over 60 years old from Shandong Province, China. ADL, MCl, social isolation and life satisfaction were respectively assessed using the daily living capacity scale for Chinese, the Montreal Cognitive Assessment (MoCA) tool, the LSNS 6 scale and the Satisfaction with Life Scale questionnaire. The multi-group SEM with latent response variable method was conducted to evaluate the association between $\mathrm{ADL}$ and $\mathrm{MCl}$ mediated by social isolation and life satisfaction.

Results: The study found that daily activity ability was negatively correlated with mild cognitive impairment in the older adults. Further analysis of mediating effect found that social isolation and life satisfaction had a partial mediating effect between $\mathrm{ADL}$ and $\mathrm{MCl}$ in the older adults.

Conclusion: These results indicated that social isolation and life satisfaction may act as a partial mediator in the relationship between $\mathrm{ADL}$ and $\mathrm{MCl}$, and the mediating effect of social isolation was more pronounced than that of life satisfaction.

\section{Background}

Mild Cognitive Impairment $(\mathrm{MCl})$ has not yet reached the level of dementia, and is somewhere between normal aging and dementia[1]. Previous large cohort studies in Europe and the United States reported that the prevalence of $\mathrm{MCl}$ in persons aged $\geq 65$ years was $7.7 \% \sim 28.3 \%$, and increased with age[2]. Numerous studies have shown that the prevalence of $\mathrm{MCl}$ is not the result of a single factor, but of a combination of factors.

There is some evidence that social isolation is associated with poorer cognitive outcomes[3]. Good social relations may also increase cognitive reserve and prevent the decline of cognitive function[4,5]. However, compared with other lifestyle factors, the relationship between social relationship and cognitive function is less clear, and the research results are contradictory[6]. Previous studies have shown that cognitive and physical functions are associated with life satisfaction[7, 8].While these studies have demonstrated a link between life satisfaction and cognitive and physical functioning[9], all but one found such a link only in bivariate analyses. Recent research also confirms that daily life activities (ADL) has been found to be a strong predictor of progression to dementia in patients in the prodromal stage of $A D[10,11]$.Elise Cornelis1 et al.[12] pointed out that $A D L$ assessment can not only be used as a diagnostic tool, but also as an indicator of future dementia risk.

There are many studies on the relationship between $A D L$ and $\mathrm{MCl}$, and only the discussion of the relationship between $A D L$ and $M C l$, but the mechanism of the potential difference is very important to reduce the impact of cognitive dysfunction in later life[13]. Currently, there are few studies on the mechanism of action between $\mathrm{ADL}$ and $\mathrm{MCl}$. Therefore, this study tries to explore the correlation between social isolation, life satisfaction, $\mathrm{ADL}$ and cognitive function. Although $\mathrm{ADL}$, social isolation and life satisfaction are closely related to $\mathrm{MCl}$, few studies have evaluated the direct influence of $A D L$ on $\mathrm{MCl}$ mediated by social isolation and life satisfaction. So far, a paucity of research examines the relationship between ADL and MCl mediating by subjective life satisfaction and life satisfaction through multi-group SEM with latent response variable approach in rural older adults.

\section{Methods}

\section{Study population}

The cross-sectional, village-based survey was conducted in 17 cities Shandong Province, from February 2018 to September 2018.In 2017, there were 21.373 million people aged 60 or above in Shandong Province, accounting for $21.4 \%$ of the this population, 4.0 percentage points higher than the national average. There are 5 cities in shandong province, which are divided into east (yantai), south (linyi), west (liaocheng), north (binzhou), central (tai 'an) according to geographical location. A two-stage cluster sampling method was adopted. First, 1 township was randomly selected from each city, and then 2 villages were selected from each township. Finally, 10 villages were selected in this study. Senior citizens who give informed consent in writting, could maintain good communication with interviewers, and have lived in their current homes/there for more than two years were included in the study. Excluded individuals were dementia, aphasia, severe deafness, old adults who could not answer questions, old adults with mental illness, old adults who refused the survey, did not complete the survey, or did not cooperate with the survey. A total of 2,933 older adults people were selected from 10 villages as research subjects.

\section{Data collection/measurement of anthropometrics}

All old adults were interviewed face-to-face by trained investigators who were undergraduates from Binzhou Medical University. Information on demographics, $\mathrm{ADL}, \mathrm{MCl}$, social isolation, life satisfaction, health-related behaviors and health status was collected by a structure questionnaire. During the survey, older adults subjects with memory impairment can be supplemented by accompanying family members to answer the questionnaire. The investigators have good investigation skills and rigorous working attitude, and they promise to keep the data confidential. The completed questionnaires were comprehensively audited to check their completeness, logicality and consistency.

\section{Assessment of general information and covariates}

The general information questionnaire contained sociodemographic variables, health-related behaviors and health-status were investigated in a unified and rigorous procedure. In this study, Sociodemographic characteristics include covariates such as age, sex, marital status, education, number of children, occupation, living arrangement,monthly income, economic domination, medical expenses burden, 
etc., which are classified as follows: age( $<70 ; 70-80 ; \geq 45 y e a r s)$, gender (male or female) ,marital status (couple vs. others), number of children(0;1;2;3+) ,occupation (manual labour or mental labour), education (primary school or below;junior school senior high school and above), living arrangement (living alone; spouse; spouse and offspring; pension institutions and others), monthly income(<1000;1000-2999; 3000-4999; $\geq 5000 \mathrm{RMB})$, economic domination (total; partial; no domination), medical expenses burden (individuals and governments). Health-related behavioral variables include smoking, drinking status, sleep duration and physical exercise frequency ,which are classified as follows: smoking status (non-smoking; smoking at present; smoking in the past), drinking status (no; yes), sleep duration ( $<5 ; 5-10 ; \geq 10$ hours/day), physical exercise frequency $(0 ; 1-2 ; \geq 3$ times/week).Smoking status refers to smoking at least one cigarette per day on average for 6 consecutive months or more, and smoking cessation status refers to smoking before but stopping smoking for more than 6 months[14].Drinking status were assessed by asking the participants whether they had drunk alcohol in the past 6 months[15].Health-status include BMI, NCDs, Self-reported health .Self-reported non-communicable diseases(NCDs) were also investigated, and NCDs in the past 1 year(yes vs. no).Weight and height were measured in this study and Body mass index(BMI) was calculated as weight( $\mathrm{kg}$ ) divided by height (m) in square. Participants were divided into 4 categories(lean, normal ,overweight and obesity), according to the China criteria[16].Self-reported health status was assessed by asking the older adults "how do you feel about your current health?", which answers are classified as good, normal or bad.

\section{Assessment of ADL}

Activity of Daily Living(ADL) Scale[17]was applied to measure activity of daily living of the older adults. It consists of two parts: one is the physical selfmaintenance scale (PSMS), which consists of six items: eating, going to the toilet, dressing, brushing, walking and taking a bath;The second item is the daily life tools activity scale (IADL), which includes 8 items: making phone calls, shopping, preparing meals, doing housework, washing clothes, using transportation, taking medicine and handling finances. The possible answers and their scores were: "I can do it all by myself" (1 point), "some difficulty" (2 point), "need help" (3 point), and "can't do it at all" (4 point). The total scores ranges from 14 to 56 . The higher the total score of ADL, the lower the daily activity ability.

\section{Assessment of social isolation}

The Lubben Social Network Scale - 6 (LSNS-6) was used to measure social isolation status of the older adults. [18]. The LSNS-6 scale is mainly used for the screening of social isolation in older population, with good reliability and validity [11]. The scale is divided into two parts: "family module" and "friend module", each module consists of 3 items with equal weight. Each item contains "no", "1", "2", "3 4", "5 8" and "nine, or even more" six level of response, assignment of $0 \sim 5$ points in turn. The scale total scores for each six items are summed and range from $0-30$, with higher scores indicating closer social ties, and vice versa. Older people with overall scores below 12 are considered "socially isolated".

\section{Assessment of life satisfaction}

The Satisfaction with Life Scale (SWLS) scale was used to measure life satisfaction of the older adults [19]. The SWLS scale includes the following five items: [1] "My life is roughly in line with my ideals." [2] "My life is in full swing." [3] "I am satisfied with my life." [4] "Until now, I've been able to get the important things I wanted in life." [5] "There are few things I would change if I could live my life over again." Participants used a seven-point Likert scale, ranging from 1 (strongly disagree) to 7 (strongly agree), to indicate how much they agreed or disagreed with each item. The overall Scores ranged from 5 to 35 , with higher scores indicating higher life satisfaction.

\section{Assessment of $\mathrm{MCl}$}

Mild cognitive impairment $(\mathrm{MCl})$ in individuals over 60 years of age was measured using the Beijing version of the Montreal Cognitive Assessment(MoCA-BJ) tool[20], which is a revision of the English version of the Montreal cognitive assessment scale based on Chinese cultural background and language features, and is also one of the most widely used versions in China. The reliability and validity of the Chinese version of the MoCA-BJ have been confirmed. The scale includes eight dimensions: visual space/executive function, naming, memory, attention, language, abstraction, delayed recall, and orientation. In addition to the memory dimension, other dimensions, such as visual spatial executive ability (5 points in total), naming (3 points in total), attention ( 3 points in total), language ( 3 points in total), abstraction ( 2 points in total), delayed memory ( 5 points in total), directional force (5 points in total), are added together to make the total score of 30 points. Higher scores imply better cognitive function, and this scale has better reliability and validity when used to evaluate the cognitive function of the population [21, 22].Most studies have shown different thresholds, ranging from 16 to 26 , although MoCA 's total score has been adjusted for education. In this study, 20 points were used as the cutoff value, and a score of < 16 points was considered as mild cognitive impairment.

\section{Ethical approval}

The study protocol was approved by the Ethical Committee of Binzhou medical college(2017-070). The investigation was performed after the acquisition of informed consent from all participants.

\section{Statistical analysis}

The data were double-entered and checked using EpiData version 3.1(The EpiData Association,Odense,Denmark). Statistical analyses were performed using SPSS version 22.0(IBM Corp., Armonk, NY) and AMSO 22.0 (IBM Corp., Armonk, NY). Continuous variables were expressed as mean \pm SD and classified variables were expressed as frequencies and percentages. The comparison of continuous variables were analyzed by students' test, while the chi-square test were carried out for classified variables. Pearson partial correlation coefficients were used to examine relationship among dimensions of daily activity ability, social isolation, life satisfaction, and each domains of $\mathrm{MCl}$ after controlling for other variables. Before regression analysis, multicollinearity diagnostics were conducted on all covariates and the two dimensions of ADL. Then, multivariable linear regression was used to evaluate the association between dimensions 
of $\mathrm{ADL}$ and each dimensions of $\mathrm{MCl}$ after controlling for relevant covariates (model a) , further adjusting for social isolation (model b) , and finally after further adjusting for life satisfaction (model c).

Moderation analyses were conducted to determine whether social isolation and life satisfaction moderates the association between ADL and MCl.A multigroup SEM with latent response variable approach was conducted via AMSO22.0 to explore how social isolation and life satisfaction might influence the association between $\mathrm{ADL}$ and $\mathrm{MCl}$ among senior citizen. Considering the measurement error and non-normality[14], social isolation and life satisfaction were considered as latent mediators variable in the mediation analysis. Given that relevant covariates (i.e., The controlled covariates were age, gender, education, occupation, marital status, number of offspring, monthly income, economic domination medical expenses burden living arrangement, smoking status, alcohol consumption, sleep duration, physical exercise, BMI, NCDs, self-reported health) may have influence on social isolation life satisfaction and MCl, these variables were adjusted in the mediation analysis. The mediation and moderated mediation model were analyzed using the PROCESS macro for SPSS[23]. The bias-corrected $95 \%$ confidence interval $(\mathrm{Cl})$ was calculated with 5000 bootstrapping re-samples[23, 24]. The indirect effect is statistically significant if the bias-corrected bootstrap $\mathrm{Cl}$ doesn't include zero[24]. All statistical tests were two-tailed and a $p$ value $<0.05$ was considered as statistically significant.

\section{Results}

\section{Characteristics of the study population}

In this study, 2,933 older adults were divided into two groups based on whether or not they had mild cognitive impairment. Table 1 shows prevalence of $\mathrm{MCl}$ among rural older adults with different characteristics. The differences of age, gender, education, occupation, marital status, number of offspring, monthly income, economic domination medical expenses burden living arrangement, alcohol consumption, sleep duration, physical exercise, BMI, NCDs, selfreported health, $T$ scores of social isolation, $A D L$, life satisfaction, scores of relatives isolation, friends isolation ,PSMS and IADL were statistically significant in the older adults with and without mild cognitive impairment $(p<0.001)$.

\section{Correlations between $\mathrm{ADL}$, social isolation, life satisfaction and $\mathrm{MCl}$}

The partial Pearson product moment correlations between ADL, social isolation, life satisfaction and MCl controlling for other covariates are summarized in Table 2. PSMS was negatively associated with Vsuospatial abilities, Naming, Attention, Language, Abstraction, Delayed recall, Orientation, Relatives Isolation, Friends Isolation and life satisfaction, but was positively associated with IADL $(p<0.001)$. IADL was negatively associated with 7 domains of $\mathrm{MCI}$, Two modules of social isolation and life satisfaction, but was positively associated with PSMS $(p<0.001)$.

\section{Multicollinearity diagnosis}

In order to identify the multicollinearity problem, we performed multicollinearity diagnosis before multiple linear regression analysis. Many studies have shown that tolerance value above 0.17 and VIF below 6 can be used to diagnose multicollinearity[25]. The results showed that all VIF were less than 4 , and all tolerance values were greater than 0.5 . Therefore, there is no sufficient evidence showing that the covariates and scores of ADL were in collinearity.

\section{The relationship between $A D L$, social isolation, life satisfaction and $\mathrm{MCl}$}

Table 3 shows the results of multiple linear regression analysis. The results showed that only among old adults IADL was significantly negatively correlated with relatives isolation and friends isolation, which were the two modules of social isolation, after adjusting for age, gender, education, occupation, marital status, number of children, monthly income, economic domination, medical expenses burden, living arrangement, smoking status, alcohol consumption, sleep duration, physical exercise, BMI, NCDs, self-reported health. Similarly, IADL was negatively correlated with life satisfaction after adjusting for the same covariate. model 4 is the association between $\mathrm{MCl}$, social isolation and $\mathrm{ADL}$ by multiple linear regression. The results of multiple linear regression analysis still showed that IADL in the older adults was negatively associated with MoCA scores after controlling for the same covariates as above. By further adjusting for social isolation, the coefficients of IADL among old adults were slightly attenuated and the friends isolation was obviously positively related with MCI. Then, further adjusting for life satisfaction variables, the results still showed a negative correlation between IADL and $\mathrm{MCl}$ although the correlation coefficient was slightly reduced, and the friends isolation and life satisfaction were obviously positively related with $\mathrm{MCl}$.

\section{Mediation analysis}

Fig. 1 displays our hypothesized relationships between $\mathrm{ADL}$, social isolation, life satisfaction and $\mathrm{MCl}$. All latent variables (denoted by ellipses) were adjusted for age, gender, education, occupation,marital status, number of offspring, monthly income,economic domination medical expenses burden living arrangement ,smoking status, alcohol consumption, sleep duration, physical exercise, BMI, NCDs, self-reported health.

Fig. 1 were statistically significant $(p<0.05)$. The results of multi-group SEM with latent response variable mediator analysis are shown in Table 4.The multigroup SEM analysis revealed that there was a partial mediation effect in the relationship between $\mathrm{ADL}$ and $\mathrm{MCl}$ through social isolation and life satisfaction. The total effect, the direct effect of $A D L$, and the indirect effect through social isolation and life satisfaction were all significant. Moreover, the results illustrated a small and negative indirect effect with statistical significance existed in old adults $(-0.016,95 \% \mathrm{Cl}:(-0.023,-0.011))$, and the percentage of indirect effect on total effect was $16.67 \%$.For the two intermediate variables in the analysis, social isolation accounted for $68.75 \%$ of the total indirect effect, which had a more significant intermediate effect than life satisfaction in the association between ADL and MCl. In addition, the CFI, TLI, RMSEA of the full samples model were $0.950,0.943$ and 0.060 , respectively. 


\section{Discussion}

Although studies have examined the relationships between ADL, social isolation , life satisfaction and MCI[2, 3], few studies have examined the relations of the four variables in a single model. To our knowledge, the current study is the first study to explore the role of social isolation and life satisfaction in the relationship between $\mathrm{ADL}$ and $\mathrm{MCl}$ in aged using the multi-group SEM with latent response variable approach.

It is well known that some aspects of social isolation are related to cognitive function in later life[3]. Social isolation may damage cognitive function, because isolated individuals have less social contact with others. These people may get less cognitive stimulation through social contact, which leads to the decrease of cognitive reserve and cognitive function[26]. The study also found that some significant and common changes in life, such as retirement, widowhood[27], financial constraints[28], mobility difficulties [29] and other factors may increase the risk of social isolation of the older adults. In the study, similar to others[30], the $\mathrm{MCl}$ of the older adults with severe social isolation was worse than that of the older adults with less social isolation.

Previous studies suggested that higher cognitive function was positively correlated with LSWS and positive emotion[31-33]. Most researchers believe that people with higher cognitive ability can better appreciate the subtle and positive aspects of life, or people are more suitable to use resources and adapt to the environment, so as to promote happiness. The longitudinal study conducted by Åsa Enkvist[9] et al. revealed the ability of life satisfaction of the older adults to predict cognitive ability. Our study also suggests that better life satisfaction can improve cognitive ability.

Studies have shown that ADL is a central marker of the diagnosis and progression of dementia syndrome[34]. A large number of studies have shown that IADL damage can predict the progression of dementia, and can be used to help distinguish dementia from early forms of cognitive decline, such as mild cognitive impairment[35].Our data also shows that after controlling age, gender, education level, occupation, marital status, number of children, monthly income, economic control, medical cost burden, living standard and other factors, the older adults with IADL disorder have a relative relationship with $\mathrm{MCl}$, and PSMS has a more obvious impact on $\mathrm{MCl}$, which is consistent with previous studies[36]. However, when the effects of social segregation were controlled, the link between $\mathrm{ADL}$ and $\mathrm{MCl}$ was slightly diminished in the older adults. Further adjustment of subjective well-being variables, although the correlation coefficient slightly decreased, but still showed that IADL and $\mathrm{MCl}$ were negatively correlated.

As expected, the poor ability of daily activities had a negative impact on cognitive function through the poor life satisfaction of self perception, while the better ability of daily activities was the opposite in the older adults. This was consistent with previous studies[37] that poor daily activities lead to poor life satisfaction and cognitive impairment, while better daily activities improve life satisfaction and stimulate cognitive rehabilitation[9]. Similarly, poor ability of daily activities leads to serious social isolation[38], which further affects the cognitive function of the older adults, while better ability of daily activities promotes good social relations, which is related to cognitive repair . In addition, our intermediary analysis shows that social isolation and life satisfaction had an impact on the relationship between $\mathrm{ADL}$ and $\mathrm{MCl}$, and the impact of $\mathrm{ADL}$ and $\mathrm{MCl}$ was partly mediated by social isolation and life satisfaction. Therefore, in addition to the pathways shown in our study, there might be other mediators that mediate the connection between ADL and MCl. However, as far as we know, the mechanism of other factors mediating the interaction between $\mathrm{ADL}$ and $\mathrm{MCI}$ has not been reported.

Although the size of indirect effects in the whole sample was relatively small, these indirect effects were indeed significant. Devaki B. Kotian[29] et al. showed that higher ADL dependency was an important factor associated with social isolation among the older adults. With the increase of dependence on ADL, the probability of being isolated from society also increases. Most studies have confirmed that there is a correlation between social connections and cognitive function in the older adults. Barnes [39]et al. Conducted a follow-up study on the older adults, which showed that there was a positive correlation between social contact and cognitive level of the older adults, and the risk of cognitive decline of the older adults with social isolation increased. Similarly, the relationship between the ability of daily activities and life satisfaction has been confirmed by many researches[40]. The limited ability of daily activities will inevitably affect the happy life experience of the individual, and then affect the cognitive ability of the older adults. The results indicate that improving the social relationship and life satisfaction of the older adults will help to improve their cognitive function.

There are also some limitations of the study needs to be addressed. First of all, the design of this study was cross-sectional, so a causal relationship between $\mathrm{ADL}$ and mild cognitive impairment mediated by social isolation and life satisfaction cannot be concluded, which needs to be confirmed by further prospective studies. Secondly, although strict quality control was applied at every step from data collection to data analysis, there might still be reporting bias. Although latent variable analysis was used to correct the bias of social isolation and life satisfaction to some extent after all, there is no objective measurement of social isolation and life satisfaction. Third, the mediating effect of social isolation and life satisfaction between ADL and mild cognitive impairment was partial, and other variables might exist in the mediating model.

\section{Conclusion}

In conclusion, these results indicated that social isolation and life satisfaction may act as a partial mediator in the relationship between $\mathrm{ADL}$ and $\mathrm{MCl}$, and the mediating effect of social isolation was more pronounced than that of life satisfaction. Future research is warranted.

\section{Abbreviations}

BMI

Body mass index

ADL

Activities of daily living

$\mathrm{MCl}$

mild cognitive impairment 


\section{Declarations}

\section{Acknowledgements}

The author would like to thank all the participants who showed great patience in answering the questionnaires.

\section{Author's contributions}

The author confirms sole responsibility for the following: study conception and design, statistical analyses and interpretation of results, and manuscript preparation. The author(s) approved the final manuscript.

\section{Funding}

This work was supported by Innovation and entrepreneurship training program for college students in Shandong Province(No.S201910440015).

\section{Availability of data and materials}

The datasets used and/or analysed during the article are available on reasonable request at jiagzh221@163.com.

\section{Ethical approval and consent to participate}

The study design was approved by the Ethical Committee of Binzhou medical college(2017-070). All older people signed informed consent before conducting a house-to-house survey.

\section{Consent to publish}

Not applicable.

\section{Conflict of intrest}

The author declares that she has no competing interests.

\section{Author details}

Department of Epidemiology,School of Public Health and Management, Binzhou Medical University, 346 Guanhai Rd, Yantai, Shandong 264003, China.

\section{References}

1. Liu X, Yin X, Tan A, He M, Jiang D, Hou Y, Lu Y, Mao Z. Correlates of Mild Cognitive Impairment of Community-Dwelling Older Adults in Wuhan, China. Int J Environ Res Public Health. 2018; 15(12).https://doi.org/10.3390/ijerph15122705.

2. Reddy H, Su X, Shang L, Xu Q, Li N, Chen J, Zhang L, Zhang L, Hua Q. Prevalence and Predictors of Mild Cognitive Impairment in Xi'an: A CommunityBased Study among the Elders. PLoS ONE. 2014;9(1):e83217. https://doi.org/10.1371/journal.pone.0083217.

3. Evans IEM, Martyr A, Collins R, Brayne C, Clare L. Social Isolation and Cognitive Function in Later Life: A Systematic Review and Meta-Analysis. J Alzheimers Dis. 2019;70(s1):119-44. https://doi.org/10.3233/JAD-180501.

4. DiNapoli EA, Wu B, Scogin F. Social Isolation and Cognitive Function in Appalachian Older Adults. Res Aging. 2013;36(2):161-79. https://doi.org/10.1177/0164027512470704.

5. Fratiglioni L, Paillard-Borg S, Winblad B. An active and socially integrated lifestyle in late life might protect against dementia. Lancet Neurol. 2004;3(6):343-53. https://doi.org/10.1016/S1474-4422(04)00767-7.

6. Kuiper JS, Zuidersma M, Zuidema SU, Burgerhof JGM, Stolk RP, Oude Voshaar RC, Smidt N. Social relationships and cognitive decline: a systematic review and meta-analysis of longitudinal cohort studies. Int J Epidemiol. 2016;45(4):1169-206. .https://doi.org/10.1093/ije/dyw089.

7. Daniela S, Jopp, Min-Kyung S, Park, Lehrfeld J, Paggi ME. Physical, cognitive, social and mental health in near-centenarians and centenarians living in New York City: findings from the Fordham Centenarian Study. BMC Geriatr. 2016;16(1):1-10. https://doi.org/10.1186/s12877-015-0167-0.

8. Allerhand M, Gale CR, Deary IJ. The dynamic relationship between cognitive function and positive well-being in older people: A prospective study using the English Longitudinal Study of Aging. Psychol Aging. 2014;29(2):306-18. https://doi.org/10.1037/a0036551.

9. Enkvist E, Elmståhl S. Associations between cognitive abilities and life satisfaction in the oldest-old. Results from the longitudinal population study Good Aging in Skåne. Clin Interv Aging. 2013;8:845-53. https://doi.org/10.2147/CIA.S45382. 
10. Stogmann E, Moser D, Klug S, Gleiss A, Auff E, Dal-Bianco P, Pusswald G, Lehrner J. Activities of Daily Living and Depressive Symptoms in Patients with Subjective Cognitive Decline, Mild Cognitive Impairment, and Alzheimer's Disease. J Alzheimers Dis. 2016;49(4):1043-50. https://doi.org/10.3233/JAD150785 .

11. Reppermund S, Sachdev PS, Crawford J, Kochan NA, Slavin MJ, Kang K, Trollor JN, Draper B, Brodaty H. The relationship of neuropsychological function to instrumental activities of daily living in mild cognitive impairment. Int J Geriatr Psychiatry. 2011;26(8):843-52. https://doi.org/10.1002/gps.2612.

12. Brayne C, Cornelis E, Gorus E, Beyer I, Bautmans I, De Vriendt P. Early diagnosis of mild cognitive impairment and mild dementia through basic and instrumental activities of daily living: Development of a new evaluation tool. PLoS Med. 2017;14(3):e1002250.

https://doi.org/10.1371/journal.pmed.1002250.

13. de Paula JJ, Albuquerque MR, Lage GM, Bicalho MA, Romano-Silva MA, Malloy-Diniz LF. Impairment of fine motor dexterity in mild cognitive impairment and Alzheimer's disease dementia: association with activities of daily living. Revista Brasileira de Psiquiatria. 2016;38(3):235-8. https://doi.org/10.1590/1516-4446-2015-1874.

14. Ma KL, Wang H, Gao X, Huang JJ, Sun CM, Qiao N, Zhang HX, Lu Q, Que XM, Li L, et al. Sleep quality mediating the association of personality traits and quality of life among underground workers and surface workers of Chinese coal mine: A multi-group SEM with latent response variable mediation analysis. Psychiatry Res. 2019;272:196-205. https://doi.org/10.1016/j.psychres.2018.12.006.

15. Hu W, Lu J. Associations of chronic conditions, APOE4 allele, stress factors, and health behaviors with self-rated health. BMC Geriatr. 2015;15:137. https://doi.org/10.1186/s12877-015-0132-y.

16. Hu H, Wang J, Han X, Li Y, Wang F, Yuan J, Miao X, Yang H, He M. BMI, waist circumference and all-cause mortality in a middle-aged and elderly chinese population. J Nutr Health Aging. 2018;22(8):975-81. https://doi.org/10.1007/s12603-018-1047-z.

17. Katz S, Ford AB, Moskowitz RW, Jackson BA, Jaffe MW. Studies of illness in the aged: the index of ADL:a standardized measure of biological and psychosocial function. JAMA. 1963;185(12):914-9. https://doi.org/10.1001/jama.1963.03060120024016.

18. Lubben J, Blozik E, Gillmann G, lliffe S, von Renteln W, Kruse JC, Beck. Stuck AE.Performance of an Abbreviated Version of the Lubben Social Network Scale Among Three European Community-Dwelling Older Adult Populations. Gerontologist. 2006;46(4):503-13. https://doi.org/10.1093/geront/46.4.503.

19. Diener E, Emmons RA, Larsen RJ. S G. The Satisfaction With Life Scale. J Pers Assess. 1985;49(1):71-5. https://doi.org/10.1207/s15327752jpa4901_13.

20. Yu Jing L, Xin J. H. The Beijing version of the montreal cognitive assessment as a brief screening tool for mild cognitive impairment:a community-based study. BMC Psychiatry. 2012;(12):156. https://doi.org/10.1186/1471-244X-12-156.

21. Nie K, Zhang Y, Wang L, Zhao J, Huang Z, Gan R, Li S, Wang L. A pilot study of psychometric properties of the Beijing version of Montreal Cognitive Assessment in patients with idiopathic Parkinson's disease in China. J Clin Neurosci. 2012;19(11):1497-500. .https://doi.org/10.1016/j.jocn.2011.11.039.

22. Nasreddine ZS, Phillips NA, Bédirian V, Charbonneau S, Whitehead V, Collin I, Cummings JL. H. C. The Montreal Cognitive Assessment, MoCA: A Brief Screening Tool For Mild Cognitive Impairment. Am Geriatr Soc. 2005;53:695-9. https://doi.org/10.1111/j.1532-5415.2005.53221.x.

23. Hayes AF, Scharkow M. The relative trustworthiness of inferential tests of the indirect effect in statistical mediation analysis: does method really matter? Psychol Sci. 2013;24(10):1918-27. https://doi.org/10.1177/0956797613480187.

24. Mackinnon DP, Lockwood CM, Williams J. Confidence Limits for the Indirect Effect: Distribution of the Product and Resampling Methods. Multivar Behav Res. 2004;39(1):99. https://doi.org/10.1207/s15327906mbr3901_4.

25. TZ K, editor. Multiple regression and beyond: An introduction to multiple regression and structural equation modeling. 3rd Ed. 2019.

26. Isobel EM, Evans DJ, Llewellyn FE, Matthews RT, Woods C, Brayne, Clare L. Social isolation, cognitive reserve, and cognition in healthy older people. PLoS ONE. 2018;(13):e0201008. https://doi.org/10.1371/journal.pone.0201008.

27. Shimada K, Yamazaki S, Nakano K, Ngoma AM, Takahashi R, Yasumura S. Prevalence of Social Isolation in Community-Dwelling Elderly by Differences in Household Composition and Related Factors: From a Social Network Perspective in Urban Japan. J aging health. 2014;26(5):807-23. https://doi.org/10.1177/0898264314531616.

28. Jang Y, Park NS, Chiriboga DA, Yoon H, Ko J, Lee J, Kim MT. Risk Factors for Social Isolation in Older Korean Americans. J Aging Health. 2016;28(1):3-18. https://doi.org/10.1177/0898264315584578.

29. Kotian DB, Mathews M, Parsekar SS, Nair S, Binu VS, Subba SH. Factors Associated With Social Isolation Among the Older People in India. J Geriatr Psychiatr Neurol. 2018;31(5):271-8. https://doi.org/10.1177/0891988718796338.

30. Maharani A, Pendleton N, Leroi I. Hearing Impairment. Loneliness, Social Isolation, and Cognitive Function: Longitudinal Analysis Using English Longitudinal Study on Ageing. Am J geriatric psychiatry: official J Am Association Geriatric Psychiatry. 2019;27(12):1348-56. https://doi.org/10.1016/j.jagp.2019.07.010.

31. Jones T, Rapport L, Hanks R, Lichtenberg P, Telmet K. Cognitive and psychosocial predictors of subjective well-being in urban older adults. Clin Neuropsychol. 2003;17(1):3-18. https://doi.org/10.1076/clin.17.1.3.15626.

32. St John PD. PR. M. Cognitive impairment and life satisfaction in older adults. Int J Geriatr Psychiatry. 2010;25(8):814-21. https://doi.org/10.1002/gps.2422.

33. Ratigan A, Kritz-Silverstein D, Barrett-Connor E. Sex differences in the association of physical function and cognitive function with life satisfaction in older age: The Rancho Bernardo Study. Maturitas. 2016;89:29-35. https://doi.org/10.1016/j.maturitas.2016.04.007.

34. Book S, Luttenberger K, Stemmler M, Meyer S, Graessel E. The Erlangen test of activities of daily living in persons with mild dementia or mild cognitive impairment (ETAM) - an extended validation. BMC Psychiatry. 2018;18(1):308. https://doi.org/10.1186/s12888-018-1886-5. 
35. De Vriendt P, Mets T, Petrovic M, Gorus E. Discriminative power of the advanced activities of daily living (a-ADL) tool in the diagnosis of mild cognitive impairment in an older population. Int Psychogeriatr. 2015;27(9):1419-27. .https://doi.org/10.1017/S1041610215000563.

36. Perneczky R, Pohl C, Sorg C, Hartmann J, Tosic N, Grimmer T, Heitele S, Kurz A. Impairment of activities of daily living requiring memory or complex reasoning as part of the $\mathrm{MCl}$ syndrome. Int J Geriatr Psychiatry. 2006;21(2):158-62. https://doi.org/10.1002/gps.1444.

37. Yoon B, Shim YS, Kim YD, Lee KO, Na SJ, Hong YJ, Oh YS, Na DL, Seo SW, Park KW, et al. Correlation between instrumental activities of daily living and white matter hyperintensities in amnestic mild cognitive impairment: results of a cross-sectional study. Neurol sciences: official J Italian Neurol Soc Italian Soc Clin Neurophysiol. 2013;34(5):715-21. https://doi.org/10.1007/s10072-012-1120-z.

38. Lara E, Caballero FF, Rico-Uribe LA, Olaya B, Haro JM, Ayuso-Mateos JL, Miret M. Are loneliness and social isolation associated with cognitive decline? Int J Geriatr Psychiatry. 2019;34(11):1613-22. https://doi.org/10.1002/gps.5174.

39. Barnes LL, Mendes de Leon CF, Wilson RS, Bienias JL, DA E. Social resources and cognitive decline in a population of older African Americans and whites. Neurology. 2004;63(12):2322-6. https://doi.org/10.1212/01.wnl.0000147473.04043.b3.

40. Sato S, Demura S, Kobayashi H. Y. N. The Relationship and Its Change with Aging between ADL and Daily Life Satisfaction Characteristics in Independent Japanese Elderly Living at Home. J Physiol Anthropol. 2002;21(4):195-204. https://doi.org/10.2114/jpa.21.195.

\section{Tables}

Table 1. Prevalence of $\mathrm{MCl}$ among Rural Elderly with Different Characteristics

a others means those who are unmarried (0.5\%), divorced $(1.4 \%)$, widowed $(22.8 \%)$.

Note:Data are presented by mean \pm SD or frequencies (percentage).

Table 2. Correlations between $\mathrm{ADL}$, social isolation and life satisfaction, and $\mathrm{MCl}$ controlling for other covariates

\begin{tabular}{|c|c|c|c|c|c|c|c|c|c|c|c|c|}
\hline & 1 & 2 & 3 & 4 & 5 & 6 & 7 & 8 & 9 & 10 & 11 & 12 \\
\hline \multicolumn{13}{|l|}{ ADL } \\
\hline 1.PSMS & 1 & & & & & & & & & & & \\
\hline 2.IADL & $0.794^{\star \star \star}$ & 1 & & & & & & & & & & \\
\hline \multicolumn{13}{|l|}{$\mathrm{MCl}$} \\
\hline 3.Vsuospatial abilities & $-0.136^{\star \star \star}$ & $-0.200^{\star \star \star}$ & 1 & & & & & & & & & \\
\hline 4.Naming & $-0.139^{\star \star \star}$ & $-0.186^{* \star *}$ & $0.363^{\star \star \star}$ & 1 & & & & & & & & \\
\hline 5.Attention & $-0.187^{\star \star \star}$ & $-0.246^{\star \star \star}$ & $0.347^{\star \star *}$ & $0.322^{\star \star \star}$ & 1 & & & & & & & \\
\hline 6.Language & $-0.135^{\star \star \star}$ & $-0.178^{\star \star \star}$ & $0.316^{\star \star *}$ & $0.258^{\star \star \star}$ & $0.569^{* * *}$ & 1 & & & & & & \\
\hline 7.Abstraction & $-0.098^{\star \star \star}$ & $-0.128^{\star \star \star}$ & $0.280^{\star \star \star}$ & $0.252^{\star \star \star}$ & $0.417^{\star \star \star}$ & $0.459^{\star \star \star}$ & 1 & & & & & \\
\hline 8.Delayed recall & $-0.086^{\star \star \star}$ & $-0.136^{\star \star *}$ & $0.282^{\star \star *}$ & $0.215^{\star \star *}$ & $0.389^{\star * *}$ & $0.391^{\star * \star}$ & $0.352^{* * *}$ & 1 & & & & \\
\hline 9. Orientation & $-0.120^{\star \star \star}$ & $-0.124^{\star \star \star}$ & $0.186^{\star \star \star}$ & $0.173^{\star \star \star}$ & $0.448^{\star \star \star}$ & $0.386^{\star \star \star}$ & $0.345^{\star \star \star}$ & $0.331^{\star \star \star}$ & 1 & & & \\
\hline \multicolumn{13}{|l|}{ Social isolation } \\
\hline 10.Relatives & $-0.081^{\star \star \star}$ & $-0.085^{\star \star \star}$ & $0.080^{\star \star \star}$ & $0.075^{\star \star \star}$ & $0.108^{\star \star \star}$ & $0.115^{\star \star \star}$ & $0.095^{\star \star \star}$ & $0.080^{\star \star \star}$ & $0.052^{\star \star}$ & 1 & & \\
\hline 11.Friends & $-0.085^{\star \star *}$ & $-0.137^{\star \star \star}$ & $0.131^{\star \star *}$ & $0.102^{\star \star \star}$ & $0.114^{\star \star \star}$ & $0.130^{\star \star \star}$ & $0.128^{\star * *}$ & $0.152^{* * *}$ & $0.065^{\star * *}$ & $0.572^{\star \star \star}$ & 1 & \\
\hline 12.life satisfaction & $-0.188^{\star \star \star}$ & $-0.222^{\star \star \star}$ & $0.038^{*}$ & $0.059^{\star *}$ & $0.118^{\star \star \star}$ & $0.070^{\star \star \star}$ & $0.043^{*}$ & $0.102^{\star \star \star}$ & $0.059^{\star \star}$ & $0.212^{\star \star \star}$ & $0.156^{\star \star *}$ & 1 \\
\hline
\end{tabular}

Note: a The controlled covariates were age, gender, education, occupation,marital status, number of offspring, monthly income,economic domination medical expenses burden living arrangement ,smoking status, alcohol consumption, sleep duration, physical exercise, BMI, NCDs, self-reported health;

$p<0.001$

$p<0.01$

Table 3.Estimated standardized coefficients between ADL, social isolation, life satisfaction, and $\mathrm{MCl}$ controlling for other covariates in rural elderly 


\begin{tabular}{|c|c|c|c|c|c|}
\hline \multirow[t]{2}{*}{ Variables } & \multirow[t]{2}{*}{$N(\%)$} & \multicolumn{2}{|l|}{$\mathrm{MCl}$} & \multirow[t]{2}{*}{$x^{2}$} & \multirow[t]{2}{*}{$P$} \\
\hline & & Yes(\%) & $\mathrm{No}(\%)$ & & \\
\hline Observations & 2933 & $638(21.8)$ & 2295(78.2) & & \\
\hline \multicolumn{6}{|l|}{ Sex: } \\
\hline Male & $1393(47.5)$ & $262(18.8)$ & 1131(81.2) & 13.511 & 0.000 \\
\hline Female & $1540(52.5)$ & $376(24.4)$ & 1164(75.6) & & \\
\hline \multicolumn{6}{|l|}{ Age: } \\
\hline$<70$ & $1028(35.0)$ & $153(14.9)$ & $875(85.1)$ & 75.256 & 0.000 \\
\hline $70-80$ & $1432(48.8)$ & $321(22.4)$ & 1111(77.6) & & \\
\hline$\geq 80$ & $473(16.1)$ & $164(34.7)$ & $309(65.3)$ & & \\
\hline \multicolumn{6}{|l|}{ Marital status: } \\
\hline Couple & $2210(75.3)$ & $425(19.2)$ & 1785(80.8) & 33.495 & 0.001 \\
\hline Others $^{a}$ & $723(24.7)$ & $213(29.5)$ & $510(70.5)$ & & \\
\hline \multicolumn{6}{|l|}{ Occupation: } \\
\hline Manual labour & $1929(65.8)$ & $475(24.6)$ & 1454(75.4) & 27.303 & 0.000 \\
\hline Mental labour & $1004(34.2)$ & $163(16.2)$ & $841(83.8)$ & & \\
\hline \multicolumn{6}{|l|}{ Education: } \\
\hline Primary school or below & $1885(64.3)$ & $500(26.5)$ & 1385(73.5) & 74.644 & 0.000 \\
\hline Junior school & $653(22.3)$ & $99(15.2)$ & $554(84.8)$ & & \\
\hline High school and above & $395(13.4)$ & $39(9.9)$ & $356(90.1)$ & & \\
\hline \multicolumn{6}{|l|}{ Monthly income(RMB): } \\
\hline$<1000$ & $1748(59.6)$ & $459(26.3)$ & 1289(73.7) & 57.661 & 0.000 \\
\hline 1000 2999 & $840(28.6)$ & $140(16.7)$ & 700(83.3) & & \\
\hline $3000 \sim 4999$ & $250(8.5)$ & $33(13.2)$ & $217(86.8)$ & & \\
\hline$\geq 5000$ & $95(3.2)$ & $6(6.3)$ & 89(93.7) & & \\
\hline \multicolumn{6}{|l|}{ Economic domination: } \\
\hline Total & $1138(38.8)$ & 215(18.9) & $923(81.1)$ & 32.495 & 0.000 \\
\hline Partial & $1628(55.5)$ & $359(22.1)$ & 1269(77.9) & & \\
\hline No & $167(5.7)$ & $64(38.3)$ & $103(61.7)$ & & \\
\hline \multicolumn{6}{|l|}{ Medical expenses burden: } \\
\hline Governments & $346(11.8)$ & $55(15.9)$ & 291(84.1) & 7.905 & 0.005 \\
\hline individuals & $2587(88.2)$ & $583(22.5)$ & $2004(77.5)$ & & \\
\hline \multicolumn{6}{|l|}{ Smoking: } \\
\hline Non-smoking & $1837(62.6)$ & $411(22.4)$ & 1426(77.6) & 2.861 & 0.239 \\
\hline Smoking at present & $820(28.0)$ & 162(19.8) & $658(80.2)$ & & \\
\hline Smoking in the past & $276(9.4)$ & $65(23.6)$ & $211(76.4)$ & & \\
\hline \multicolumn{6}{|l|}{ Drinking: } \\
\hline Yes & 1132(38.6) & 198(17.5) & $934(82.5)$ & 19.668 & 0.000 \\
\hline No & $1801(61.4)$ & $440(24.4)$ & $1361(75.6)$ & & \\
\hline \multicolumn{6}{|l|}{ Sleep duration(hours/day): } \\
\hline$<5$ & $204(7.0)$ & $58(28.4)$ & 146(71.6) & 27.742 & 0.000 \\
\hline $5-10$ & $2316(79.0)$ & 456(19.7) & $1860(80.3)$ & & \\
\hline$\geq 10$ & $413(14.0)$ & $124(30.0)$ & $289(70.0)$ & & \\
\hline
\end{tabular}




\section{Physical exercise frequency(times/week):}

\begin{tabular}{llllll}
\hline 0 & $1409(48.0)$ & $386(27.4)$ & $1023(72.6)$ & 53.948 & 0.000 \\
\hline $1-2$ & $906(30.9)$ & $164(18.1)$ & $742(81.9)$ & & \\
$\geq 3$ & $618(21.1)$ & $88(14.2)$ & $530(85.8)$ & & \\
\hline Living Arrangement: & & & & & \\
\hline Living alone & $418(14.2)$ & $115(27.5)$ & $303(72.5)$ & 39.928 & 0.000 \\
\hline Spouse & $1574(53.7)$ & $297(18.9)$ & $1277(81.1)$ & & \\
\hline Spouse and offspring & $534(18.2)$ & $100(18.7)$ & $434(81.3)$ & & \\
\hline offspring & $384(13.1)$ & $117(30.5)$ & $267(69.5)$ & & \\
\hline others & $23(0.8)$ & $9(39.1)$ & $14(60.9)$ & & \\
\hline
\end{tabular}

\section{Number of offspring:}

\begin{tabular}{|c|c|c|c|c|c|}
\hline 0 & $66(2.2)$ & 18(27.3) & $48(72.7)$ & 15.244 & 0.002 \\
\hline 1 & $242(8.3)$ & $47(19.4)$ & 195(80.6) & & \\
\hline 2 & $934(31.8)$ & $167(17.9)$ & $767(82.1)$ & & \\
\hline $3+$ & 1691(7.7) & $406(24.0)$ & $1285(76.0)$ & & \\
\hline \multicolumn{6}{|l|}{ BMI: } \\
\hline Lean & $206(7.0)$ & 64(31.1) & $142(68.9)$ & 18.291 & $<0.001$ \\
\hline Normal & $1518(51.6)$ & $348(22.9)$ & $1170(77.1)$ & & \\
\hline Overweight+ & 983(33.6) & $184(18.7)$ & 799(81.3) & & \\
\hline obesity & $226(7.7)$ & $42(18.6)$ & 184(81.4) & & \\
\hline \multicolumn{6}{|l|}{ NCDs: } \\
\hline Yes & $1847(63.0)$ & $433(23.4)$ & $1414(76.6)$ & 8.380 & 0.004 \\
\hline No & $1086(37.0)$ & 205(18.9) & $881(81.1)$ & & \\
\hline \multicolumn{6}{|l|}{ Self-reported health: } \\
\hline Bad & $331(11.3)$ & $89(26.9)$ & $242(73.1)$ & 17.547 & 0.000 \\
\hline Normal & $2055(70.1)$ & $463(22.5)$ & 1592(77.5) & & \\
\hline Good & $547(18.6)$ & $86(15.7)$ & $461(84.3)$ & & \\
\hline Social isolation : & $14.9 \pm 5.0$ & $13.2 \pm 5.2$ & $15.4 \pm 4.9$ & -9.337 & 0.000 \\
\hline Relatives isolation & $8.1 \pm 2.3$ & $7.4 \pm 2.8$ & $8.3 \pm 2.7$ & -7.425 & 0.000 \\
\hline Friends isolation & $6.8 \pm 2.9$ & $5.8 \pm 3.1$ & $7.1 \pm 2.8$ & -9.287 & 0.000 \\
\hline ADL: & $17.3 \pm 6.3$ & $20.6 \pm 9.0$ & $16.45 \pm 5.0$ & 11.022 & 0.000 \\
\hline PSMS & $6.8 \pm 2.0$ & $7.6 \pm 3.1$ & $6.5 \pm 1.5$ & 8.454 & 0.000 \\
\hline IADL & $10.6 \pm 4.6$ & $13.0 \pm 6.3$ & $9.9 \pm 3.7$ & 11.643 & 0.000 \\
\hline Life satisfaction : & $25.8 \pm 6.3$ & $24.3 \pm 6.6$ & $26.2 \pm 6.2$ & -6.401 & 0.000 \\
\hline
\end{tabular}




\begin{tabular}{|c|c|c|c|c|c|c|c|c|c|c|c|c|}
\hline & $\begin{array}{l}\text { Social } \\
\text { isolation }\end{array}$ & & & & $\begin{array}{l}\text { Life } \\
\text { satisfaction }\end{array}$ & & $\mathrm{MCl}$ & & & & & \\
\hline & Relatives & & Friends & & & & & & & & & \\
\hline & Model $1^{\mathrm{a}}$ & & Model2 $^{\mathrm{a}}$ & & Model $^{a}$ & & Model $^{\mathrm{a}}$ & & Model $4^{\mathrm{b}}$ & & Model5c & \\
\hline & Estimate & $\mathrm{P}$ value & Estimate & $\mathrm{P}$ value & Estimate & $\mathrm{P}$ value & Estimate & P value & Estimate & $P$ value & Estimate & P va \\
\hline \multicolumn{13}{|l|}{$A D L$} \\
\hline PSMS & -0.039 & 0.208 & 0.066 & 0.034 & -0.034 & 0.270 & 0.025 & 0.402 & 0.015 & 0.607 & 0.016 & 0.59 \\
\hline IADL & -0.083 & $<0.0001$ & -0.195 & $<0.0001$ & -0.234 & $<0.0001$ & -0.273 & $<0.0001$ & -0.255 & $<0.0001$ & -0.245 & $<0.0$ \\
\hline \multicolumn{13}{|l|}{$\begin{array}{l}\text { Social } \\
\text { isolation }\end{array}$} \\
\hline Relatives & & & & & & & - & - & 0.039 & 0.067 & 0.037 & 0.07 \\
\hline Friends & & & & & & & - & - & 0.136 & $<0.0001$ & 0.132 & $<0.0$ \\
\hline $\begin{array}{l}\text { Life } \\
\text { satisfaction }\end{array}$ & & & & & & & - & - & - & - & 0.039 & 0.02 \\
\hline $\begin{array}{l}\text { R squre/ } \\
\text { adjusted R } \\
\text { squre }\end{array}$ & & & & & & & 0.173 & 0.171 & 0.189 & 0.187 & 0.189 & 0.18 \\
\hline
\end{tabular}

Note: ${ }^{a}$ adjusting age, gender, education, occupation,marital status, number of offspring, monthly income,economic domination medical expenses burden living arrangement ,smoking status, alcohol consumption, sleep duration, physical exercise, BMI, NCDs, self-reported health;

b further adjusting social isolation;

c even further adjusting life satisfaction;

model 1 is the association between relative isolation and ADL by multiple linear regression;

model 2 is the association between friends isolation and ADL by multiple linear regression;

model3 is the association between life satisfaction and ADL by multiple linear regression;

model 4 is the association between $\mathrm{MCl}$, social isolation and $\mathrm{ADL}$ by multiple linear regression;

model 5 is the association between $\mathrm{MCl}$, social isolation, life satisfaction and $\mathrm{ADL}$ by multiple linear regression;

Table 4.Mediation analysis of ADL, social isolation, life satisfaction, and $\mathrm{MCl}$

\begin{tabular}{|c|c|c|c|c|c|c|c|}
\hline Hypothesized model & $\beta$ & $P$ Value & $95 \% \mathrm{Cl}$ & $\mathrm{CFI} / \mathrm{TLI}$ & $\chi^{2}$ & $d f$ & $\begin{array}{l}\text { RMSEAWald } \\
(95 \% \mathrm{Cl})\end{array}$ \\
\hline $\mathrm{ADL} \rightarrow$ social isolation $\rightarrow \mathrm{MCl}$ & & & & $0.950 / 0.943$ & 1201.870 & 104 & $0.060(0.057,0.063)$ \\
\hline \multicolumn{8}{|l|}{$\mathrm{ADL} \rightarrow$ life satisfaction $\rightarrow \mathrm{MCl}$} \\
\hline Total effect & -0.096 & 0.001 & $-0.114,-0.080$ & & & & \\
\hline Indirect effect & -0.016 & 0.001 & $-0.023,-0.011$ & & & & \\
\hline social isolation (Me1) & -0.011 & 0.001 & $-0.016,-0.007$ & & & & \\
\hline life satisfaction (Me2) & -0.005 & 0.001 & $-0.009,-0.002$ & & & & \\
\hline Direct effect & -0.080 & 0.001 & $-0.095,-0.067$ & & & & \\
\hline
\end{tabular}

Note: adjusting age, gender, education, occupation,marital status, number of offspring, monthly income,economic domination medical expenses burden living arrangement ,smoking status, alcohol consumption, sleep duration, physical exercise, BMI, NCDs, self-reported health.

\section{Figures}




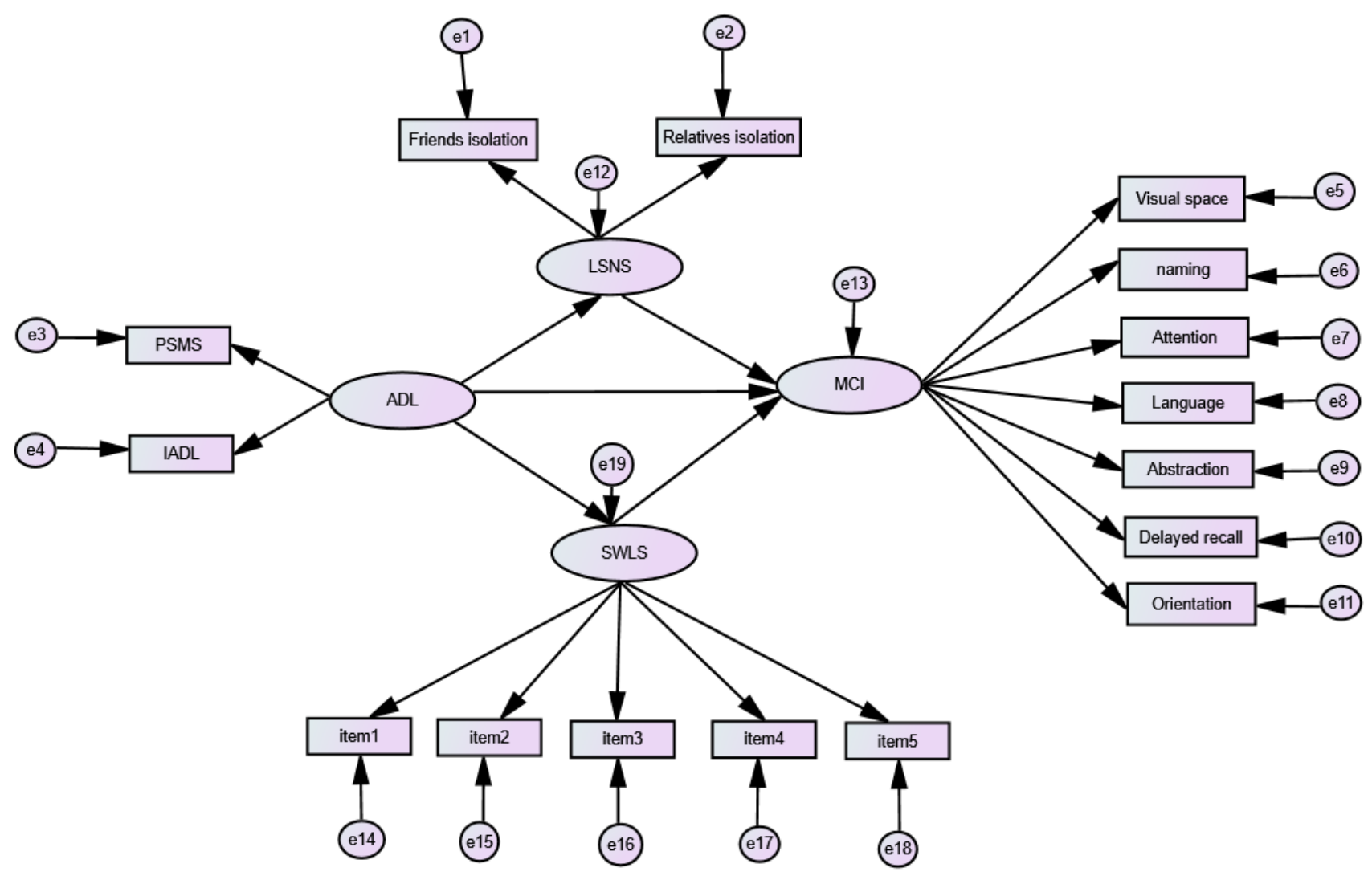

Figure 1

Standardized estimation of the relationship between ADL, social isolation(LSNS), Life satisfaction (SWLS) and MCI.

\section{Supplementary Files}

This is a list of supplementary files associated with this preprint. Click to download.

- Hypotheticalmodel.docx 